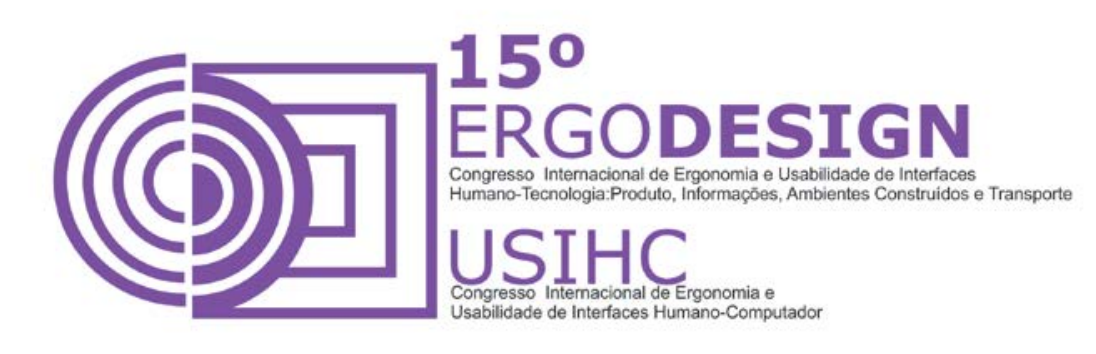

\title{
ASPECTOS DO ERGODESIGN E DA SINTAXE VISUAL APLICADOS À ANÁLISE DE CARTAZES DE FILMES DO GÊNERO COMÉDIA ROMÂNTICA
}

\section{ERGODESIGN AND VISUAL SYNTAX ASPECTS FOR ANALYSIS APPLIED TO FILM POSTERS OF ROMANTIC COMEDY GENRE}

\author{
GUILHERMINO, Amanda Eggert (1); \\ GOBBO, Lucas de Lima (2); \\ ZERBETTO, Cristiane A. de A. (3) \\ (1) Graduanda em Design Gráfico, Universidade Estadual de Londrina. \\ e-mail: amanda eqgert@hotmail.com \\ (2) Graduando em Design Gráfico, Universidade Estadual de Londrina. \\ e-mail:lucas.uck@hotmail.com \\ (3) Doutora em Energia na Agricultura, Universidade Estadual de Londrina. \\ e-mail:cra@uel.br

\begin{abstract}
RESUMO
O estudo a seguir traz uma análise, em duas vertentes, de cartazes de filmes do gênero Comédia Romântica que são estruturalmente parecidos. Do ponto de vista sintático, há uma análise dos elementos componentes da peça e da organização visual destes e do ponto de vista ergonômico, aborda - se aspectos da acuidade visual, envolvendo principalmente a cor e a tipografia.
\end{abstract}

Palavras-chave: Ergodesign, Cartazes, Comédia romântica

\section{ABSTRACT}

The study then presents an analysis in two parts, the movie posters of the Romantic Comedy genre that are structurally similar. From the syntactic point of view, there is an analysis of the elements of the poster and the organization of these visual and from the ergonomic point of view, aspects of visual acuity, mainly involving the color and typography are addressed.

Keywords: Ergodesign, Posters, Romantic Comedy 


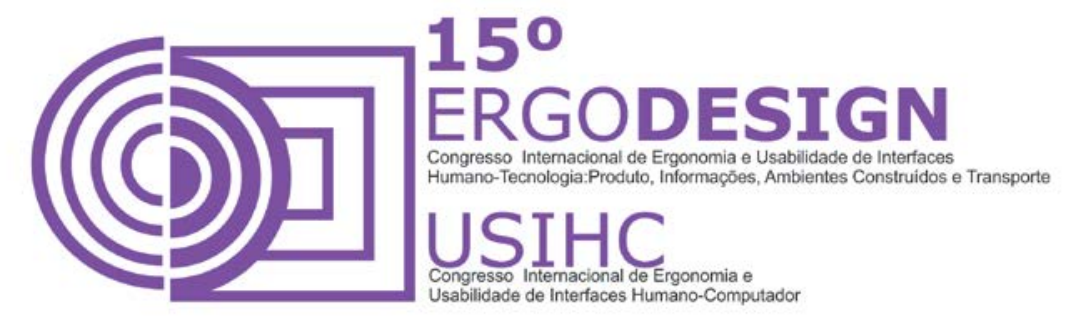

\section{INTRODUÇÃO}

O mundo do entretenimento está hoje vinculado à mídia e à tecnologia de ponta.

Cada vez mais nota - se a crescente produção de filmes dos mais variados temas, utilizando dos recursos visuais e efeitos especiais que enriquecem a narrativa. Assim sendo, em meio de tantos lançamentos, e a produções cada vez mais ricas, os Estúdios precisam investir em divulgação inteligente, que atinja o maior número de espectadores possíveis.

Nesse sentido, o estudo a seguir analisa alguns cartazes usados para a divulgação dos filmes, em particular os do gênero "Comédia Romântica", do ponto de vista da Sintaxe Visual e da Ergonomia (Ergodesign), apontando como a disposição e utilização dos elementos influenciam na composição da peça.

\section{FUNDAMENTAÇÃO CARIOCA}

\subsection{Cinema}

O cinema é considerado imagem sonora, segundo Machado (2011, p.11). É uma arte muito popular desde meados do século XX, e que a cada década surpreende com seu legado.

Para a autora, o cinema é fruto da modernidade. A rapidez com que se progrediu no início do século passado provocou uma mudança na função do artista em relação a sua produção. "(...) O artista moderno tinha um papel criativo a desempenhar na definição da essência da humanidade". (MACHADO, 2011, P.16). Em outras palavras, não mais se reproduziria ideias, mas as criaria. Assim sendo, "o fluxo de transformações, ambiguidades e contradições percebido na vida diária influenciou a sensibilidade estética." (MACHADO, 2011, p. 17).

Toda essa mudança urbana e social acarretou em um novo padrão de vida, constituído por sujeitos mais críticos e competentes. Com isso, surge a necessidade de registro de atividades, para estudo e análise. Nesse contexto, surge a fotografia. Entretanto, a imagem estática constitui - se em um objeto pobre para análises, pois na maioria das vezes, eram cenas manipuladas e preparadas. Havia a necessidade de registrar - se o movimento. Para tanto, o desenvolvimento de instrumentos que captassem uma sequência de imagem deu início ao que futuramente foi chamado de cinema.

\section{$2.2 \quad$ Ergodesign}

O Ergodesign é um conceito que traz a ergonomia aplicada no processo do projeto de design. Essa junção transforma o produto final não só em um projeto atrativo, mas amigável do ponto de vista do consumidor, devido a inserção do estudo ergonômico utilizado. O Ergodesign é indispensável para aumentar o bem-estar e o desempenho dos produtos. 


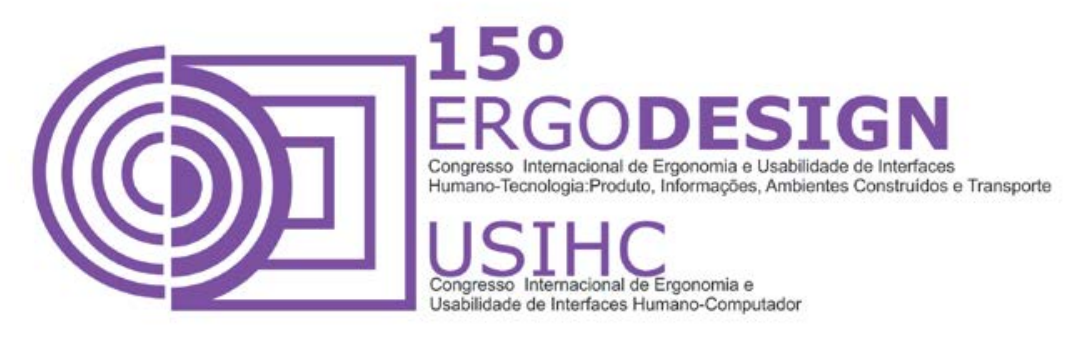

"A pesquisa ergonômica objetiva adaptar o trabalho (...) às capacidades humanas, de modo a facilitar o trabalho(...)." (MONT'ALVÃO, DAMAZIO, 2008 p.20)

\subsubsection{Acuidade Visual}

Segundo lida (2005, p. 84), a Acuidade Visual é a capacidade para discriminar pequenos detalhes. Ela depende principalmente do iluminamento e tempo de exposição. O autor explica que quanto maior a incidência de luz, maior prejuízo tem a acuidade, devido à contração da pupila. Dentre os elementos que compõem os cartazes analisados, sob o ponto de vista da acuidade visual, discorreremos sobre cor e tipografia.

\subsubsection{Cor}

Segundo lida (2005, p.86), cor pode ser traduzida em comprimentos de ondas eletromagnéticas. O olho humano é capaz de decodificar esses comprimentos, possibilitando a existência das cores. Elas são identificadas principalmente pelos cones, um tipo de célula fotossensível localizada na fóvea. Os comprimentos de onda são decodificados nessa região, mesmo com afastamento gradual. Cores como vermelho e amarelo são visíveis até $50^{\circ}$ de afastamento, o verde até $65^{\circ}$ e o branco, $90^{\circ}$. Essas ondas são consequência da reflexão da luz sobre os objetos, emitindo informações decifradas pelo olho.

Um dos principais aspectos do estudo da cor é o contraste, que está diretamente ligado ao comprimento de onda de cada cor. Cores como o violeta e o vermelho tem comprimentos opostos (370nm e $750 \mathrm{~nm}$, respectivamente), e quando colocadas juntas geram um alto grau de contraste e desconforto visual. Já o verde e azul tem comprimentos análogos, e quando usadas juntas conferem harmonia, característica importante para a escolha da cor em um projeto.

Entrando na questão da visibilidade de cores, lida $(2005$, p.481, 482) destaca que a cor atrai a atenção e prende a vista, de acordo com o grau de visibilidade. A visibilidade depende grandemente do contraste e da pureza da cor. Com relação a legibilidade de cores ele aponta que ela depende do contraste entre figura e fundo e tende a aumentar com a adição de preto à figura, com fundo claro. Outros fatores influenciam a legibilidade, como o nível de iluminação e o movimento relativo entre a imagem e o espectador. A memória das cores segundo ainda 0 mesmo autor está relacionada à tendência que as pessoas tem de incluir, na mesma categoria, objetos de cores semelhantes entre si. Essa tendência pode ser usada para agrupar objetos que tenham a mesma função.

\subsubsection{Tipografia}




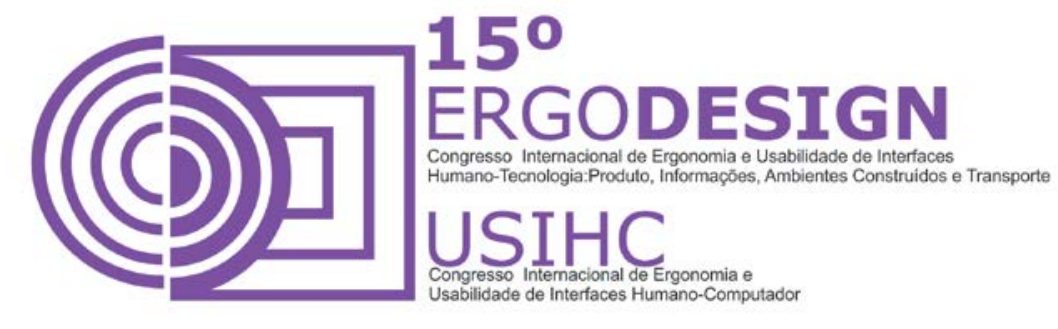

A tipografia deve atender a requisitos ergonômicos básicos. Segundo Dul e Weerdmeester (1995, p.56), as letras devem ser sempre minúsculas, exceto em começo de frases, nomes próprios e siglas. Um texto mais extenso composto por caixa alta exclusivamente prejudica a leiturabilidade. Outro aspecto que interfere na leitura de um texto, segundo os autores é a presença ou não da serifa (sendo as não-serifadas as com melhor legibilidade) (DUL; WEERDMEESTER, 1995, p.57). Deve - se ainda garantir que a família tipográfica não contenha caracteres semelhantes, que interferirão na fluidez de leitura, e que haja um bom contraste entre texto - fundo. "Quanto menor o contraste, tanto menor fica o campo de leitura e tanto mais limitada a legibilidade" (GRANDJEAN, 1998, p.213). Para uma boa leiturabilidade, "o tamanho das letras maiúsculas deve ser pelo menos $1 / 200$ da distância de leitura." (DUL, WEERDMEESTER, 1995, p.58).

\section{METODOLOGIA}

Esta pesquisa foi embasada no método qualitativo. “(...) Os procedimentos qualitativos se baseiam em dados de texto e imagem, tem passos únicos na análise de dados e usam estratégias de investigação" (CRESWELL, 2007, p.184).

Será utilizada a análise formal ou discursiva, cujo objetivo é "deslindar a estrutura da complexidade dos objetos" (DEMO, 2006, p.39). Toda a análise teve como base uma revisão teórica sobre os seguintes assuntos, importantes para a amigabilidade junto ao usuário: acuidade visual, legibilidade da tipografia e uso da cor.

Os objetos de estudo selecionados para análise foram os cartazes de divulgação dos filmes: My Girl (Meu Primeiro Amor), Wild Target (Matador em Perigo), Pretty Woman (Uma Linda Mulher), No Reservations (Sem Reservas), Two Weeks Notice (Amor a Segunda Vista) e Kiss \& Kill (Par Perfeito).

\section{DESENVOLVIMENTO DA ANÁLISE}

A produção fílmica nas últimas décadas cresceu de maneira desenfreada e rápida. Por ano, são lançados centenas de filmes, e cada um deles requer uma divulgação diferenciada. Entretanto, com a agilidade do mundo moderno, e a necessidade de identificação rápida e eficaz do estilo do filme, os designers adotaram, consciente ou inconscientemente, um padrão gráfico para a construção dos cartazes de divulgação.

No que se refere ao gênero trabalhado (Comédia Romântica), é possível perceber, a grosso modo, os elementos dispostos da seguinte maneira: o casal protagonista em destaque, de pé no centro ou levemente deslocado para uma das extremidades, virados de costas um para o outro; a tipografia varia entre serifada ou não serifada; e as cores são na maioria das vezes quentes, em especial o vermelho, já que este representa simbolicamente, em algumas culturas, o amor. 


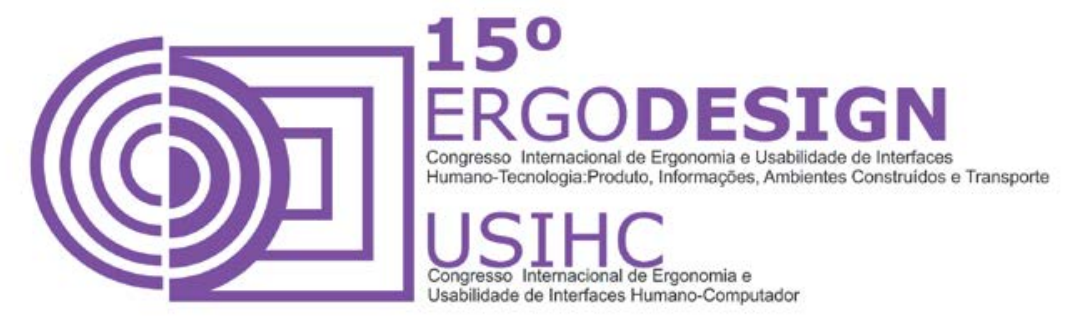

Ergonomicamente, as cores utilizadas não apresentam comprimentos de onda distantes, o que confere maior amigabilidade visual ao projeto; a tipografia apresenta grande contraste figura e fundo, aumentando a legibilidade; e a composição do grid das peças e da combinação tipográfica contribuem positivamente para a acuidade visual.

Em um olhar mais detalhado, as singularidades de cada cartaz é colocada de forma que o leitor identifique no filme mais ou menos ação, a descontração ou seriedade, etc. Por exemplo, o direcionamento do olhar ou a maior interação entre eles e a presença ou ausência do sorriso são fatores que ajudam o usuário a decifrar o conteúdo do filme com maior precisão.

A seguir são apresentadas as análises discursivas individuais de cada cartaz, apontando os aspectos sintáticos e ergonômicos dos mesmos.

\subsection{My Girl (Meu Primeiro Amor)}

No cartaz do filme My Girl, percebe - se os atores mirins posando de forma descontraída, com

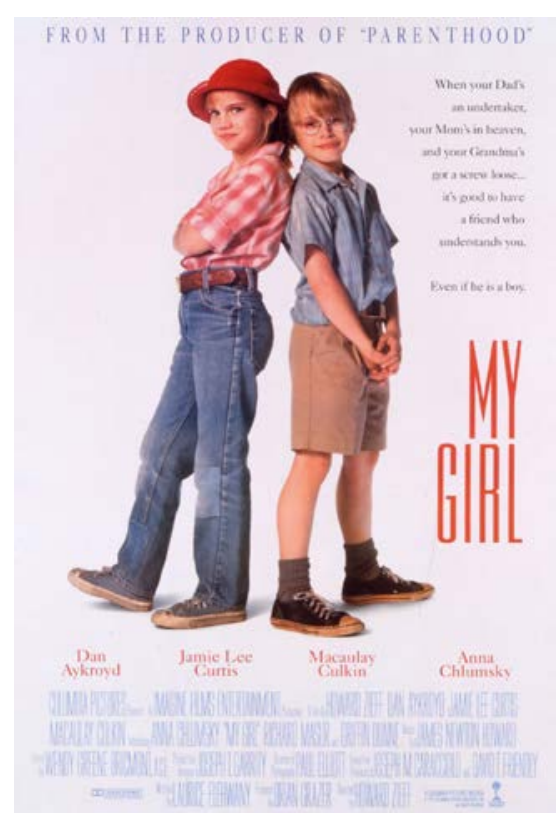
ar inocente, cada um agindo conforme as características do personagem no filme: mesmo um indivíduo que desconheça a obra, compreende que a garota é despojada, e o garoto, em contrapartida, é reservado, detalhes que podem ser extraídos a partir da análise pictográfica.

No que concerne à sintaxe visual, identifica - se o uso de cores contrastantes: azul e vermelho, ambos para a tipografia. Entretanto, o designer teve o cuidado de equilibrar a composição com tons apropriados das cores e uma boa área de respiro visual (branco), evitando o desconforto que esta combinação pode causar, construindo assim uma peça agradável. A hierarquia dos elementos constrói um sentido de leitura onde os atores e o título do filme, são os primeiros elementos, e os dados técnicos, lista de atores e sinopse são segundos elementos, não necessariamente nessa ordem. São usadas três tipografias distintas: para o título "My Girl", uma tipografia não serifada, do tipo slim; para o nome de atores e produtores, uma tipografia serifada; e para os créditos, uma comumente usada para esse fim. A escolha dessas tipografias não desrespeita a acuidade visual, visto que existe uma harmonia entre elas.

Já no aspecto ergonômico, o cartaz segue algumas regras essenciais. Segundo Dul e Weerdmeester (1995), um texto longo não deve ser escrito com todos os tipos maiúsculos. Entretanto, a frase "From the producer of 'Parenthood'" não segue essa regra, tendo todas as suas letras maiúsculas, comprometendo a leiturabilidade da sentença. O título não teve sua 

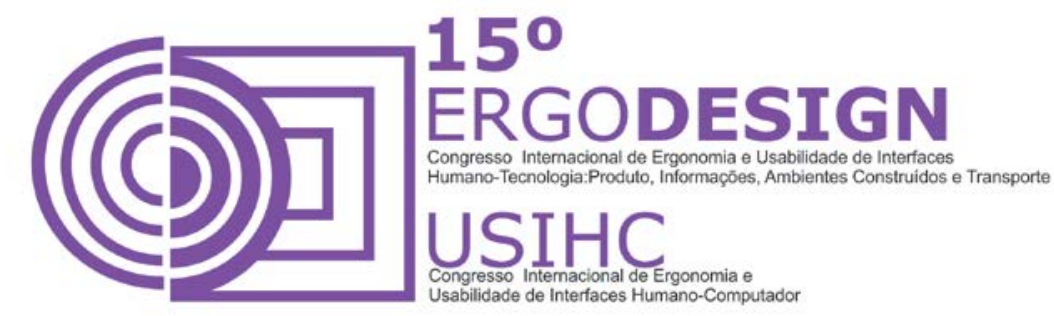

leiturabilidade comprometida, pois é composto apenas de 2 palavras. No que se refere aos demais textos, o criador teve o cuidado de evitar construções em maiúscula.

Outra regra seguida foi a de uso de tipografia sem serifa para o título, que é preferível para essas construções. Existe um ótimo contraste figura e fundo, aumentando a legibilidade, e o tamanho das letras estão adequados à função delas no contexto. Ou seja, o título tem tamanho maior que a lista do elenco, por exemplo, e é facilmente reconhecido a certa distância. Como já dito na análise sintática, o cartaz apresenta cores contrastantes, de espectro 436-495 nm para o azul e 627 - $780 \mathrm{~nm}$ para o vermelho. Porém, é interessante perceber que o uso foi deliberado, aplicando os tons insaturados, evitando desconforto. O fundo também apresenta um tom amigável ao consumidor da peça, garantindo uma acuidade visual sem perturbações.

\subsection{Wild Target (Matador em Perigo)}

Já o cartaz do filme Wild Target remete a um romance mais aventureiro, percebido pela menor

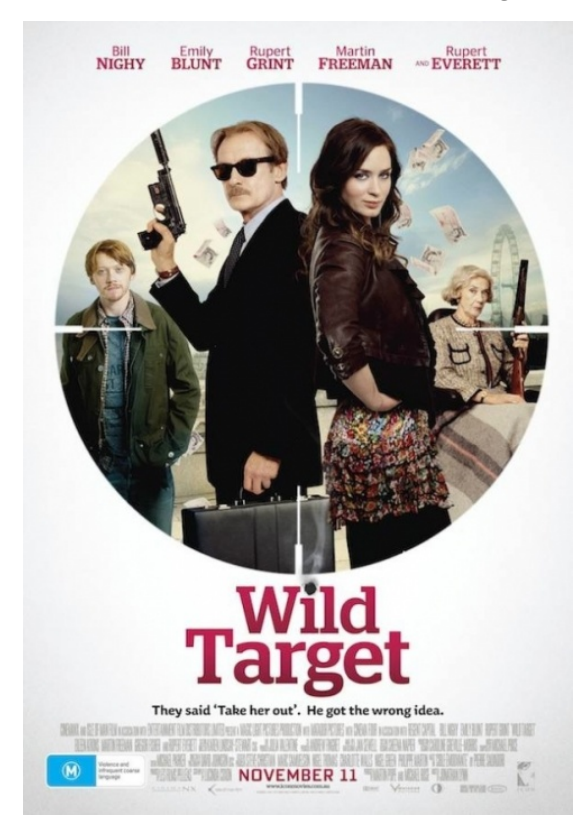
interação entre os personagens e o olhar desafiador deles. Essa peça em particular traz além do casal principal, outros personagens na composição que têm papeis secundários na trama, mas igualmente importante ao dos protagonistas. Todos os quatro estão inseridos em um círculo que simula uma mira de arma (observando os detalhes nas extremidades), direcionando o olhar para o casal central. $\mathrm{O}$ fundo do cartaz apresenta um gradiente radial do cinza para o branco que reforça o destaque dado ao círculo.

O designer utilizou três cores harmônicas: cinza insaturado, branco e rosa, as primeiras para o fundo e a última para a tipografia (exceto para os dados técnicos). O sentido de leitura resume - se, como na análise de My Girl, o casal e o título como primeiros elementos, os personagens de trás como segundos elementos, e o restante como terceiros elementos. A tipografia alterna entre serifada e não serifada: encontra - se serifa no título e no sobrenome dos atores, mas não a encontramos no nome deles e na frase de efeitos do filme, localizada abaixo do título. Outro detalhe é o uso de marca de tiro para simbolizar o pingo do "i", reforçando a ideia de uma Comédia Romântica mais aventureira.

No aspecto ergonômico, o cartaz segue algumas das indicações descritas por Grandjean (1998) e Dul e Weerdmeester (1995). No que se refere à tipografia, para o texto continuo, foi usada alternância entre minúscula e maiúscula, facilitando a leitura, devido a fluidez que essa construção agrega. 


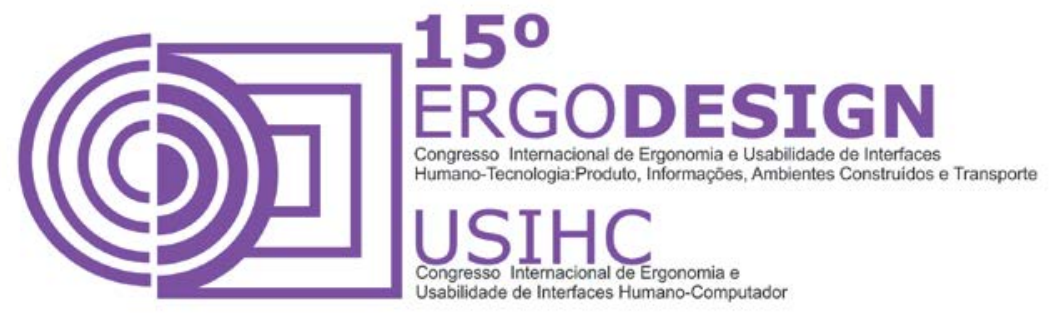

O uso de apenas caracteres maiúsculos aparece para palavras isoladas, não comprometendo a leiturabilidade. Segundo princípios ergonômicos, referenciados por Dul e Weerdmeester (1995), para títulos prefere - se tipografia não - serifada. Entretanto, essa peça utiliza uma serifada, podendo esta escolha estar atrelada à seriedade a ser transmitida pelo título. Além disso, a interação entre as palavras "Wild" e "Target" parece inapropriada, uma vez que o encaixe da primeira acima da segunda não funcionou bem, ocasionando uma descentralização, por vezes incômoda.

Contudo, a hierarquia das tipografias está correta, diferenciando elementos menos e mais importantes pelo corpo delas. Aquilo que deve ser visto de longe está em tamanhos maiores.

A cor rosa, utilizada sobre esse fundo, apresenta um bom contraste, facilitando a legibilidade. A aplicação de cor quente em tons não muito saturados não causa irritabilidade visual, deixando a composição harmônica. O uso equilibrado do tom rosa em palavras localizadas estrategicamente não provoca um desconforto, já que não há um bombardeio de informações utilizando essa cor. Outro aspecto que reduz a fadiga visual é o equilíbrio entre a cor rosa com a cor preta, dentro da tipografia, evitando uma sobrecarga da primeira cor.

\subsection{Pretty Woman (Uma Linda Mulher)}

Para essa análise, foi selecionado uma versão mais minimalista do cartaz do filme. A peça

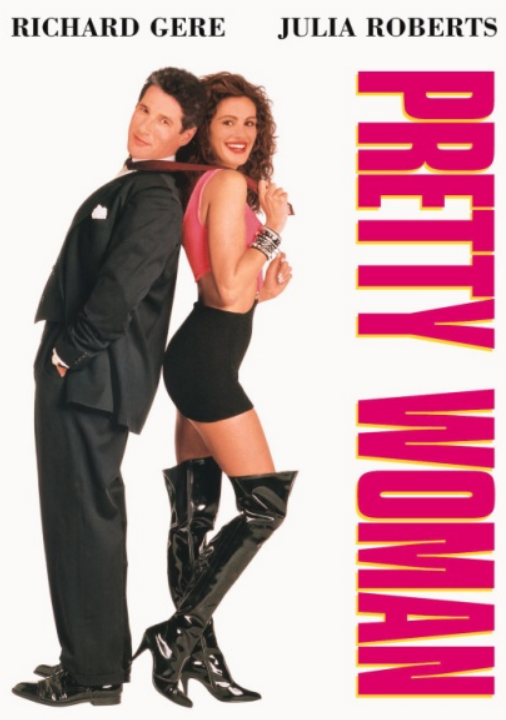
apresenta apenas a figura do casal (e o nome dos respectivos atores) e o título do filme.

A presença do sorriso declara a vivacidade e alegria presente na trama. Cabe destacar ainda a presença do elemento sedução, que é traduzido pela maneira como Julia Roberts segura a gravata, e pelo estilo de roupa utilizado, chamando a atenção para o corpo da atriz.

Sintaticamente, é um cartaz com alto grau de minimalismo. As cores da parte gráfica se repetem na fotografia (uma vez que as roupas dos atores condizem com as cores das tipografias). A tríade de cores rosa $x$ preto $x$ branco encontra - se equilibrada. Para uma transição menos brusca da cor rosa do título para o fundo branco, foi acrescido uma camada duplicada das palavras "Pretty Woman", utilizando a cor amarela, e levemente deslocada em relação ao texto original. A tipografia do título é completamente adequada, uma vez que o seu peso tipográfico é alto, chamando mais a atenção. O sentido de leitura é completamente vertical e descendente. 


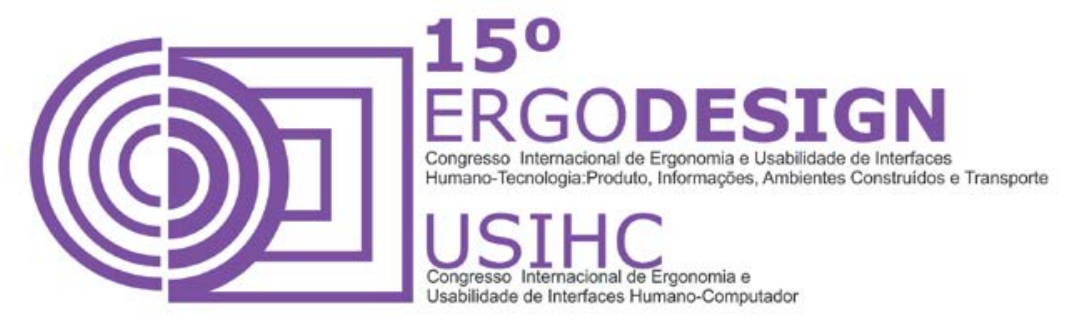

No aspecto ergonômico, o cartaz trabalha com duas cores quentes na construção do título, sendo que elas apresentam pouca diferença no espectro luminoso, contribuindo para uma visualização amigável da composição. A combinação com o fundo também está de acordo com os padrões ergonômicos, uma vez que não há irritabilidade visual. A tipografia escolhida para o nome dos atores está adequada em relação ao título, ou seja, seu tamanho respeita a sua função na peça (menor tamanho), enquanto o título recebe maior destaque. Esse por sua vez, não apresenta serifa, aspecto indicado para títulos, e pode ser visto facilmente a distância. A composição em si apresenta boa acuidade visual, sendo amigável para os usuários.

\subsection{No Reservations (Sem Reservas)}

O cartaz do filme No Reservations traz os protagonistas centralizados e posicionados de forma

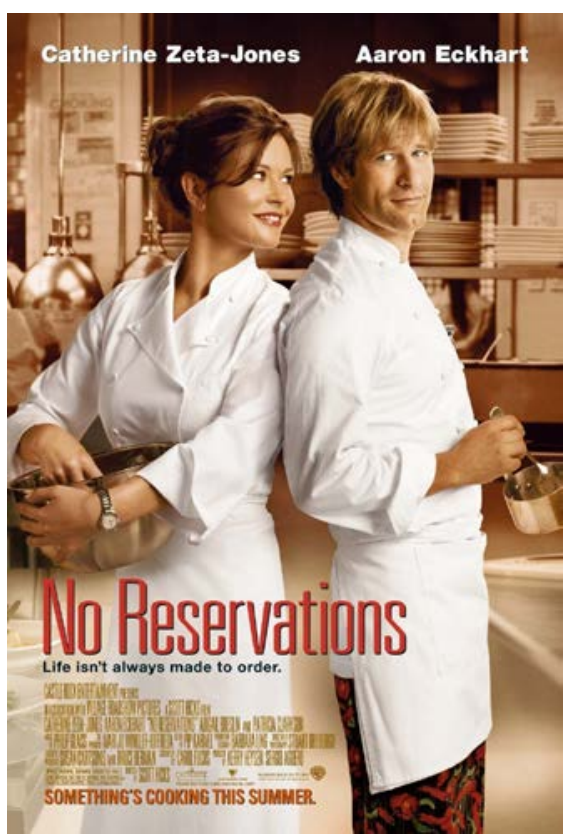
oposta. Porém, eles conseguem tornar esse posicionamento muito íntimo considerando o fato de estarem apoiados um ao outro e o deslocamento do pescoço e olhar da atriz em direção ao ator. São essas singularidades que dão o diferencial de cada cartaz de filme nos quesitos abordados anteriormente como mais ou menos ação, a descontração ou seriedade, etc.

No que diz respeito à sintaxe visual observa-se o equilíbrio da peça como um todo. Eles apostam em um cenário de fundo que caracteriza o ambiente principal da trama, que é a cozinha. Os objetos usados pelos protagonistas reforçam esse envolvimento com o lugar e o ato de cozinhar juntos. A hierarquia das informações segue um padrão, que é o nome dos atores na região superior, o destaque para a imagem dos atores e do título, seguido pelos créditos na parte inferior do cartaz.

A tipografia não serifada está de acordo com o que Dul e Weerdmeester (1995) dizem sobre a melhor legibilidade desses tipos quando olhados a distância, o uso de maiúsculas e minúscula ajudam na leiturabilidade de quase todo o cartaz, fugindo à essa norma apenas a frase "Something's cooking this summer".

A paleta de cores vai do vermelho a tons de marrom, sendo que as cores predominantes do cartaz são os tons avermelhados, e o filtro usado no cenário ao fundo de cor vermelho terroso deixa em destaque a roupa branca das figuras principais. Essa escolha de cores deu ao cartaz uma acuidade visual harmônica, sem chances de causar irritabilidade aos observadores do cartaz, além de dar um ar bucólico romântico que retrata muito da história desenvolvida neste filme. 

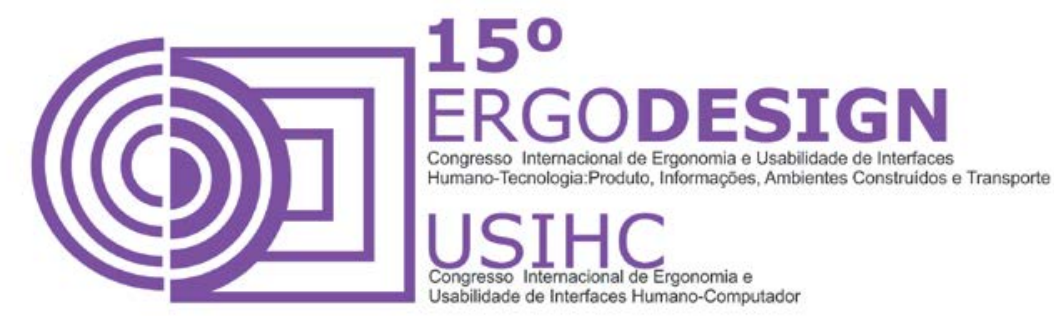

\subsection{Kiss \& Kill (Par perfeito)}

Neste cartaz observa - se uma grande semelhança com o cartaz do filme Pretty Woman. Os

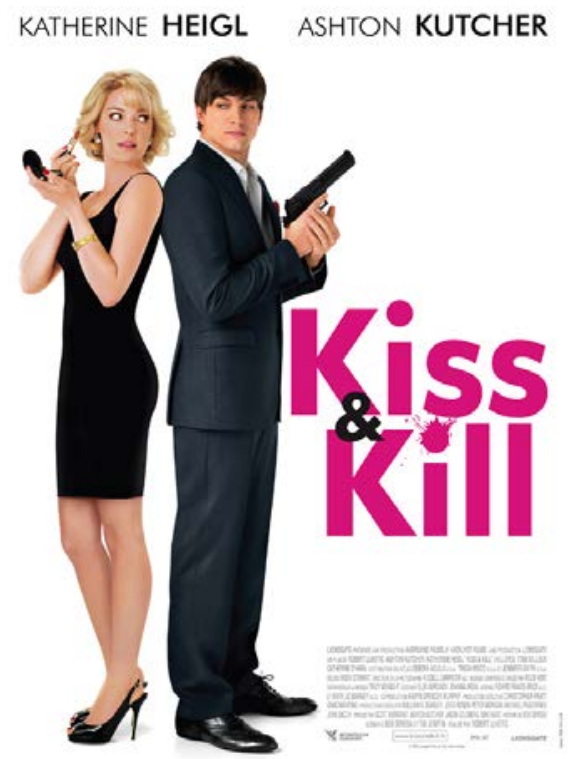
protagonistas estão posicionados de forma oposta com deslocamento para a esquerda da peça e o nome do filme está situado à direita. $\mathrm{O}$ cartaz aqui em destaque tem sua hierarquia semelhante aos demais, com o nome dos atores na parte superior, destaque central para a figura e título e logo abaixo os créditos.

O filme Kiss \& Kill é sem dúvida uma comédia romântica de ação e cumplicidade. Os protagonistas tem olhares desafiadores e sedutores, como se estivessem competindo e ao mesmo tempo tentando a conquista mútua. Os elementos, maquiagem e arma, completam essa dualidade.

A tipografia escolhida é sem serifa em todo o cartaz e atende às indicações já mencionadas neste artigo, que são a leiturabilidade e legibilidade desses tipos não serifados, que é muito adequado para esta aplicação.

As cores utilizadas são o pink, preto e branco, que possuem alto contraste, mas são bem utilizadas, sem poluir o cartaz. Pode - se exemplificar dando destaque à grande área branca do fundo do cartaz, que já deixa a visualidade confortável, sendo que o pink está aplicado no título e subtítulo de forma correta (alto destaque) sem comprometer a acuidade visual. O preto é utilizado nos demais textos.

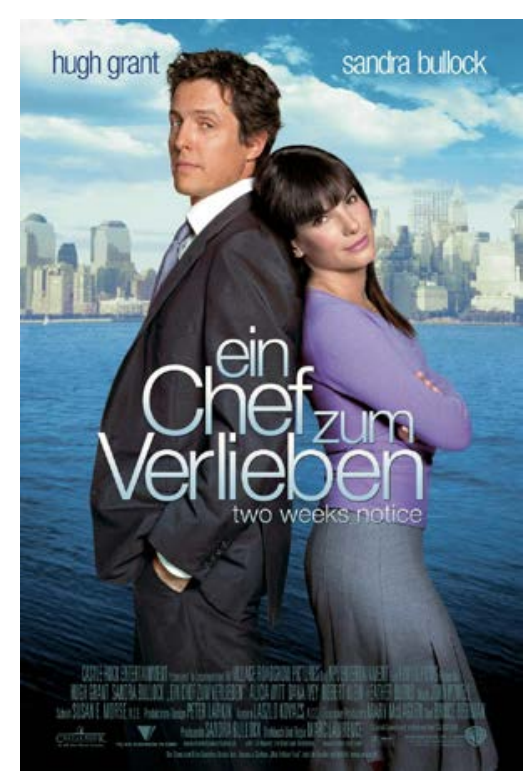

\subsection{Two Weeks Notice (Amor a segunda vista)}

O cartaz tem o posicionamento oposto dos protagonistas com uma leve inclinação da cabeça da figura da direita sobre o ombro da figura da esquerda e um olhar de recémapaixonados ou redescobertos. Esta sensação está inserida também no título do filme. A hierarquia segue a mesma dos demais, com leves alterações: nome de atores, destaque para figura e título, seguido pelos créditos na região inferior.

Este cartaz difere - se um pouco dos demais devido às cores escolhidas. Os cartazes aqui analisados, em sua maioria, possuem uma paleta de cores quentes (em especial tons de rosa e vermelho), exatamente pelo fato de serem cores que estão ligadas ao amor. Contudo, os tons escolhidos para esta 


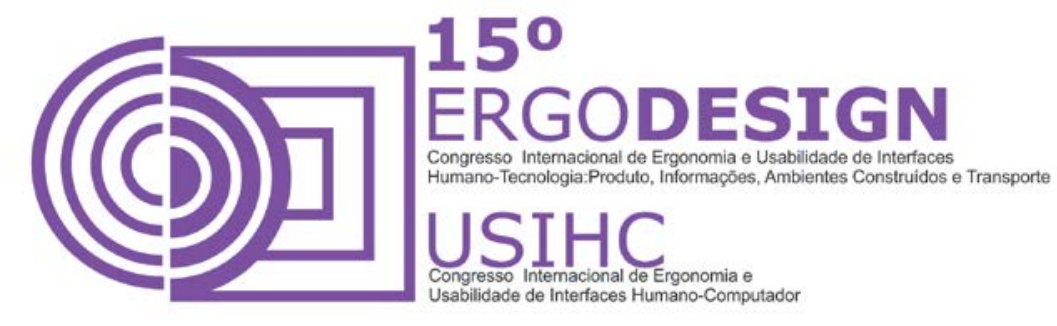

trama foram tons de azul, cinza e lilás. São cores que traduzem a serenidade e naturalidade desse reencontro. A figura da cidade ao fundo retrata o cenário do romance e vem com os tons de azul que é aplicado também à tipografia em um degradê do branco ao azul.

Os tipos escolhidos para a este cartaz é não serifado, confirmando a adequação destes tipos neste segmento de cartazes.

\section{CONCLUSÃO}

A partir das análises, pôde - se constatar que, apesar de visualmente semelhantes e com muitos pontos em comum, cada um desses cartazes apresentam uma singularidade, percebida através de uma análise mais profunda do que apenas a contemplação estética da obra.

Todos eles, por terem sido desenvolvidos por designers competentes, atendem em grande parte as indicações dos fatores ergonômicos observados (não em sua totalidade, visto algumas exceções apresentadas na análise). Com isso, percebemos que existe um cuidado, não apenas com o produto em si, mas com aqueles que vão consumi - lo, que no caso de cartazes, aprecia - lo em cinemas ou locadoras, por exemplo. Conclui - se que com o cumprimento de regras para melhor acuidade visual, o filme pode ter melhores desempenhos no que diz respeito à bilheteria ou venda dos produtos subsequentes (DVD's, Bluray's, etc). A partir do momento em que existe grande amigabilidade visual, existe uma resposta positiva para a divulgação, percebida nos resultados colhidos.

Portando, podemos dizer que quanto maior a preocupação com a ergonomia visual, melhores os resultados para a divulgação da obra.

\section{REFERÊNCIAS BIBLIOGRÁFICAS}

DUL, Jan; WEERDMEESTER, Bernard. Ergonomia prática. São Paulo: Blücher, 1995.

GRANDJEAN, Etienne. Manual de ergonomia: adaptando o trabalho ao homem. Porto Alegre: Bookman, 1998.

HELLER, Steven. Linguagens do design: compreendendo o design gráfico. São Paulo: Rosari, 2007.

IIDA, Itiro. Ergonomia: projeto e produção. São Paulo: Blücher, 2005.

MACHADO, Ludmila Ayres. Design e linguagem cinematográfica: narrativa visual do projeto. São Paulo: Blucher, 2011.

MONT'ALVÃO, Cláudia; DAMAZIO, Vera. Design, Ergonomia, Emoção. Rio de Janeiro: Mauad X, 2008. 


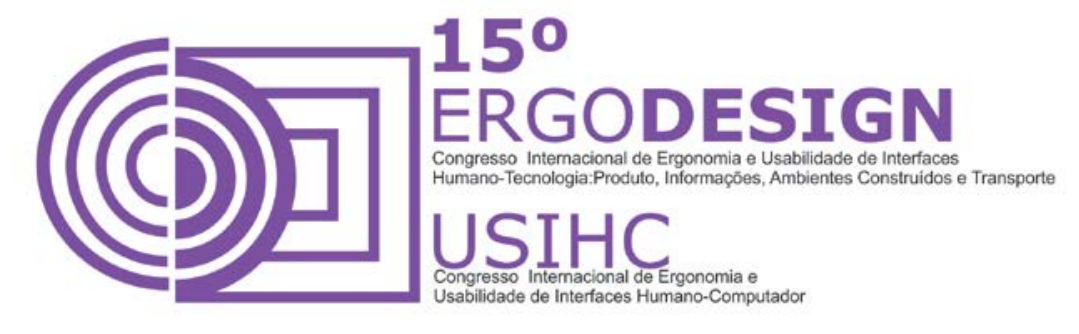

STRAUSS, Anselm; CORBIN, Juliet. Pesquisa qualitativa, técnicas e procedimentos para o desenvolvimento de teoria fundamentada. Porto Alegre: Bookman, 2008. 